\title{
Application and evaluation of universal kriging for optimal contouring of groundwater levels
}

\author{
B V N P Kambhammettu ${ }^{1, *}$, Praveena Allena ${ }^{2, * *}$ and James P King ${ }^{1, \dagger}$ \\ ${ }^{1}$ Civil Engineering Department, New Mexico State University, \\ MSC 3CE, Box No. 30001, Las Cruces, NM-88003, USA. \\ ${ }^{2} 301$ S Tin St., Deming, NM-88030, USA. \\ *e-mail: phani@nmsu.edu \\ **e-mail: Praveena.Allena@state.nm.us \\ $\dagger$ †-mail: jpking@nmsu.edu
}

This paper deals with the application of universal kriging to interpolate water table elevations from their measurements at random locations. Geographic information system tools were used to generate the continuous surface of water table elevations for the Carlsbad area alluvial aquifer located to the southeast of New Mexico, USA. Water table elevations in the 38 monitoring wells that are common to 1996 and 2003 irrigation years follows normal distribution. A generalized MATLAB ${ }^{\circledR}$ code was developed to generate omni-directional and directional semi-variograms (at 22.5 intervals). Low-order polynomials were used to model the trend as the water table profile exhibits a south-east gradient. Different theoretical semivariogram models were tried to select the base semi-variogram for performing geostatistical interpolation. The contour maps of water table elevations exhibit significant decrease in the water table from 1996 to 2003. Statistical analysis performed on the estimated contours revealed that the decrease in water table is between 0.6 and $4.5 \mathrm{~m}$ at $90 \%$ confidence. The estimation variance contours show that the error in estimation was more than $8 \mathrm{~m}^{2}$ in the west and south-west portions of the aquifer due to the absence of monitoring wells.

\section{Introduction}

Successful management of groundwater resources using numerical models requires knowledge of spatial distribution of hydraulic heads, aquifer parameters and other input data (Kumar and Ramadevi 2006). Geostatistical techniques play a vital role in sustainable management of groundwater system by estimating the model input parameters at regular grid points from their measurements at random locations (Kumar 2007). Geostatistics is a collection of techniques for solving estimation problems involving spatial variables (Journal and Huijbregts 1978). It offers a variety of tools including interpolation, integration and differentiation of hydro-geologic parameters to produce the prediction surface and other derived characteristics from measurements at random locations (ASCE Task Committee 1990a). Geostatistical techniques (such as kriging, co-kriging and universal kriging) have the capability of producing a prediction surface, and also provide some measure of capability of these predictions (Johnston et al 2001). The spatial variability of the random

Keywords. Geostatistics; estimation variance; semi-variogram; universal kriging; geographic information system (GIS). 
variable is characterized by co-variance or semivariogram functions, which are the key elements in estimation techniques (Gundogdu and Guney 2007). ArcGIS provides a variety of tools (such as Spatial Analyst ${ }^{\circledR}$ and Geostatistical Analyst ${ }^{\circledR}$ ) in order to explore spatial data, evaluate the prediction uncertainty and create surfaces for efficient decision making in geo-hydrology (Johnston et al 2001).

Application of universal kriging (UK) to interpolate water table altitudes for the Ogallala aquifer in Kansas during 1978 was studied by Dunlap and Spinazola (1984). A total of 1859 data points were used to construct the kriged surface of water levels for 1978 and an average period of 1978-1980. An estimated trend in the data led to the application of UK using the residual approach. The centre of section technique was used to construct maps of saturated thickness of the aquifer from the kriged water table and bed rock altitude estimates. Application of UK to interpolate water levels and hydraulic conductivities from their measurements at random locations for the Potomac-RaritonMagothy aquifer system in central New Jersey was studied by Pucci and Murashige (1987). Directional semi-variograms were developed by dividing the area surrounding each interpolation point into four quadrants. A computer program was used to generate the empirical semi-variogram and crossvalidation statistics. Based on the prediction error map, authors have suggested the areas of highest priority for additional data collection. Application of UK to interpolate the mean annual precipitations from the data at 362 meteorological stations in Slovenia during 1961-1990 was studied by Kastelec and Koŝmelj (2002). The study area was divided into two parts based on the rain gauge density map. Two perpendicular axes with maximum difference in spatial continuity were obtained from the generated variogram maps using Gstat $2.0 \mathrm{~g}$ program. The effect of influential surrounding (defined by an ellipse) on the kriged variance was investigated. The quality of kriged predictions was presented in the form of histogram of residuals obtained from cross-validation. The authors observed that predictions in the eastern part of Slovenia were more reliable due to a higher density of meteorological stations to characterize the spatial variability. The UK methodology for estimating the gradient of head from scattered data was illustrated by Igúzquiza and Olmo (2004). Hydraulic head data from 43 measurements in the Vega de Granada aquifer in southern Spain was considered for the analysis. Gradients were estimated in particular directions and the results were presented in the form of maps of maximum and mean gradient for the whole aquifer. Every estimated map was provided with a standard error map to show the reliability of the estimation. The method of UK to spatially analyse the groundwater levels for the Musafakemalpasa left bank irrigation scheme in Turkey was presented by Gundogdu and Guney (2007). The study was aimed at finding out the best semi-variogram with a linear trend that resulted in acceptable results in predicting the water table values based on the monthly observation data for 2002. Normality of the measured dataset was checked from the skewness values of the histogram. Log transformation was used to adjust the water table values to normal distribution. Results of the least significant difference (LSD) test estimated that the nature of the semi-variogram has almost insignificant effect in predicting the water table surface. Kumar (2007) applied UK to generate the contour map of groundwater levels to a command area in northwestern India. Water table elevations from the 143 observation wells during September 1990 were used to prepare experimental semi-variograms using a FORTRAN code. The trend order was estimated by the cross-validation procedure using residual approach. The UK-interpolated water levels were then compared by inverse distance weighted estimates. Normality of the measured water levels was checked using chi-square goodness of fit test. Areas prone to water logging were generated by combining the kriged surface with the ground elevation map. The author concluded that the UK-predicted groundwater levels at the monitoring well locations satisfactorily matched with the observed levels.

Geographic Information System (GIS) is widely used to collect, store, retrieve and analyse spatially distributed hydro-geologic data. However, application of GIS tools to generate the prediction surface and error in prediction is limited especially when a trend in the dataset is observed. This is because, identifying the two perpendicular axes with maximum difference in semi-variogram values is difficult. This paper presents the use of GIS tools to generate the water table surface and the error in estimation from randomly measured groundwater levels when the regionalized variable exhibits a trend. Geostatistical Analyst ${ }^{\circledR}$ tool in ArcGIS is used to explore the spatial variability in water table elevations for the Carlsbad area alluvial aquifer located in south-east New Mexico. Water table elevation data at the 38 monitoring wells that are common to 1996 and 2003 datasets are considered for the analysis. A generalized MATLAB ${ }^{\circledR}$ code is developed to generate omnidirectional (by ignoring the direction) and directional semi-variograms (at $22.5^{\circ}$ intervals) for analysing the trend in the datasets. Different theoretical variogram models (including spherical, Gaussian and exponential) were tried 
to select a suitable base model that satisfies the statistical conditions. Finally, the contour map of water table elevations and the error in prediction surface are prepared to infer on the spatial variation of groundwater table in the region. A statistical analysis on the interpolated water levels was performed during 1996 and 2003 to comment on the temporal variation in the water table.

\section{Methodology}

Kriging is an interpolation technique that uses observations $z\left(x_{i}\right)$ at location $x_{i}$ to estimate the values $z\left(x_{0}\right)$ at point $x_{0}$, where the observation is not available (Kumar 2007). The random variable $z$ at any location can be written as the sum of a deterministic component called trend $m(x)$ and a stochastic error component $R(x)$. For any distance vector $h$, the increment $z(x+h)-z(x)$ has zero expectation and finite variance, which is independent of location $x$ (intrinsic assumption) (Journal and Huijbregts 1978). The variance of this increment defines semi-variogram given by:

$$
\gamma=\frac{1}{2} \operatorname{Var}[z(x+h)-z(x)]
$$

The experimental semi-variogram (by grouping the data pairs according to their distances) from the measured data points can be obtained by:

$$
\begin{aligned}
\gamma^{*}(|h|)= & \frac{1}{2 N(|h|)} \\
& \times \sum_{i=1}^{N(|h|)}\left[z\left(x_{i}+h^{\prime}\right)-z\left(x_{i}\right)\right]^{2},
\end{aligned}
$$

where $z\left(x_{i}\right)$ is the measured value at location $x_{i}$; $z\left(x_{i}+h^{\prime}\right)$ is the measured value at location $x_{i}+h^{\prime}$; $|h|$ is the average distance between the pairs of data points that belongs to a distance class; $N(|h|)$ is the number of pairs of data points that belongs to the distance interval represented by $h$.

Linear geostatistics estimates the expected value $z\left(x_{0}\right)$ at location $x_{0}$ as the weighted sum of the known data $z\left(x_{1}\right), z\left(x_{2}\right), \ldots, z\left(x_{n}\right)$ taken to be realizations of $z(x)$ at $x_{1}, x_{2}, \ldots, x_{n}$ (Rouhani 1989) such that:

$$
z^{*}\left(x_{0}\right)=\sum_{i=1}^{n}\left[\lambda_{i} z\left(x_{i}\right)\right]
$$

where $\lambda_{i}$ is the weights chosen to satisfy the following statistical conditions.

The first condition requires the estimator $z^{*}\left(x_{0}\right)$ to be unbiased resulting in:

$$
\sum_{i=1}^{n} \lambda_{i}=1
$$

The second condition requires the estimator $z^{*}\left(x_{0}\right)$ to have minimum variance of estimation.

$2 \sum_{i=1}^{n} \lambda_{i} \cdot \gamma_{i 0}-\sum_{i=1}^{n} \sum_{j=1}^{n} \lambda_{i} \cdot \lambda_{j} \cdot \gamma_{i j}=$ minimum

where $\gamma_{i j}=\gamma\left(\left|x_{i}-x_{j}\right|\right)$.

The minimization of equation (5) subjected to the condition in equation (4) is achieved by the Lagrangian method, and this form of linear interpolation is referred to as kriging. In simple kriging, the mean (the trend component $m(x)$ ) is assumed to be constant and known prior to kriging. In ordinary kriging, the mean is assumed to be constant but has to be estimated. When the regionalized variable exhibits a trend, the assumption of the stationarity of the mean is violated, leading to a nonstationary interpolation technique. A method that provides an estimator when a trend is present in the measured dataset is called universal kriging (Isaaks and Srivastava 1989). Solution from UK requires an additional dataset to deal with the unbiasedness condition. The trend can be modelled with a polynomial given by:

$$
m(x)=\sum_{p=1}^{l} a_{p} \cdot f_{p}(x),
$$

where $a_{p}$ is the $p^{\text {th }}$ coefficient; $f_{p}$ is the $p^{\text {th }}$ basic function that describes the trend; $l$ is the number of functions used in modelling the trend. The additional condition to be satisfied is given by:

$$
\sum_{i=1}^{n} \lambda_{i} \cdot f_{p}\left(x_{i}\right)=f_{p}\left(x_{0}\right)
$$

The UK with $l$ number of unbiasedness conditions is found by minimizing the variance of estimation given in equation (5) subjected to the condition in equation (7) resulting in the following simultaneous equations represented in matrix form. 


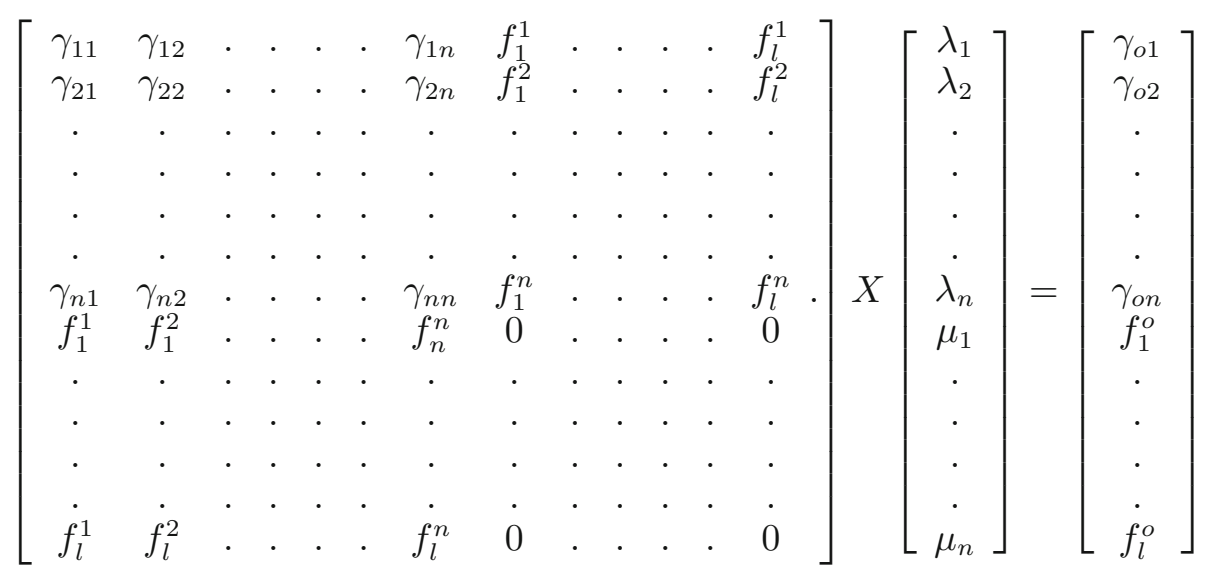

where $\gamma_{i j}$ is the underlying semi-variogram between points $x_{i}$ and $x_{j} ; f_{p}^{j}$ is $f_{p}\left(x_{j}\right) ; \mu_{p}$ is the Lagrangian multiplier associated with $p$ th unbiasedness condition. The estimation variance of UK is given by:

$$
\sigma_{\mathrm{uk}}^{2}=\left\{\sum_{i=1}^{n} \lambda_{i} \cdot \gamma_{i o}\right\}+\left\{\sum_{p=1}^{l} \mu_{p} f_{p}\left(x_{o}\right)\right\}-\gamma_{o o} .
$$

UK is applied when the regionalized variable exhibits some form of trend (Isaaks and Srivastava 1989). The main difficulty with UK is the circular nature of the problem. To determine the trend, the underlying semi-variogram must be known, but to determine the semi-variogram, the trend must be known (since the semi-variogram is found from the residuals $z(x)-m(x))$. In the present analysis, the residual approach (ASCE Task Committee 1990a, $1990 \mathrm{~b}$ ) is followed to resolve the problem, in which polynomials (of different orders) are used to model the trend within the local neighbourhood. The residuals are then calculated by direct subtraction of the polynomial trend from the measured values to determine the semi-variogram. As a semivariogram is needed initially to calculate the trend, the solution requires an iterative process that uses a base semi-variogram to calculate the trend and residuals and then re-calculate the semi-variogram from the residuals. The differences between the estimated and observed values (defined as residuals) at the measured locations are summarized using the cross-validation statistics given by:

$$
\mathrm{ME}=\frac{1}{N} \sum_{i=1}^{N}\left[z^{*}\left(x_{i}\right)-z\left(x_{i}\right)\right]
$$

$$
\begin{aligned}
\mathrm{MSE} & =\frac{1}{N} \sum_{i=1}^{N}\left[z^{*}\left(x_{i}\right)-z\left(x_{i}\right)\right]^{2}, \\
\mathrm{KRMSE} & =\frac{1}{N} \sum_{i=1}^{N} \frac{\left[z^{*}\left(x_{i}\right)-z\left(x_{i}\right)\right]^{2}}{\sigma_{u k . i}^{2}},
\end{aligned}
$$

where $N$ is the number of data points used in estimating residual statistical parameters. The trend order and the theoretical semi-variogram that results in close to zero mean error (ME); minimum mean square error (MSE); and kriged reduced mean square error (KRMSE) near to 1 are chosen as final model parameters for geostatistical interpolation.

\section{Case study}

Capitan aquifer in the Carlsbad area of New Mexico is situated between the townships $22 \mathrm{~S}$ to $24 \mathrm{~S}$ and ranges $26 \mathrm{E}$ to $28 \mathrm{E}$. The study area, as shown in figure 1 is located in the Eddy County of south-east New Mexico with an aerial extent of $424 \mathrm{~km}^{2}$. It is bounded on the north by the Seven Rivers Hills, on the west by the Guadalupe Mountains, on the south by the Black River Valley and on the east by the Pecos River. The average annual precipitation within the study area ranges from $13^{\prime \prime}(33 \mathrm{~cm})$ in the Pecos Valley near Carlsbad to $22^{\prime \prime}(56 \mathrm{~cm})$ near the west of the Guadalupe Mountains. The alluvium is recharged by precipitation, floods in ephemeral streams, subsurface inflow and by seepage from irrigation. Groundwater is discharged from the alluvium by wells, subsurface outflow and seepage along the Pecos River (Bjorklund and Moths 1959). In general, groundwater flow in the basin and shell facies is primarily 

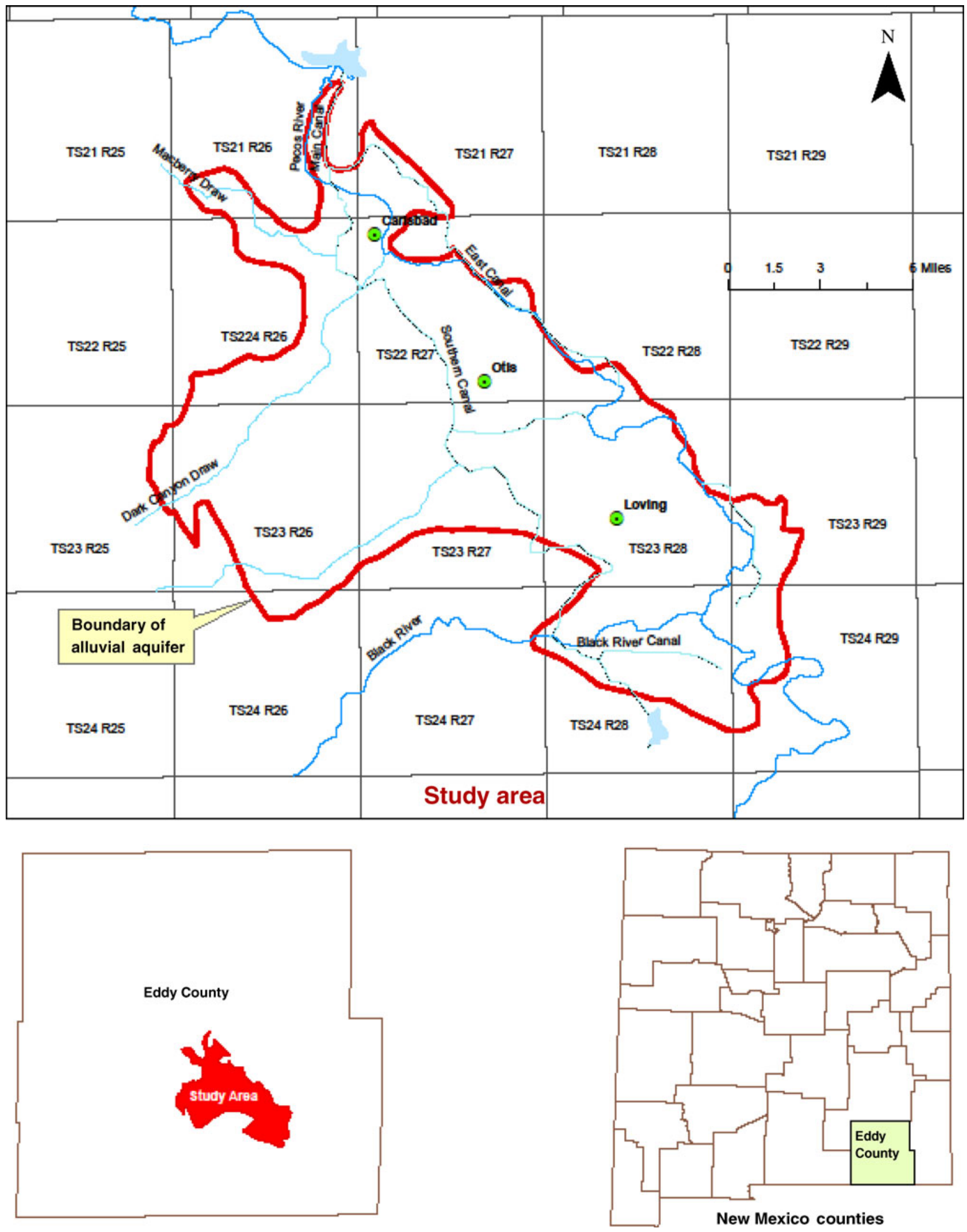

Figure 1. Map of New Mexico counties with study area.

towards the east. The high permeability of the Capitan aquifer resulted in concentrated flow along the trend of the reef, generally towards the north and northeast. The water table in the alluvial aquifer is at or near the land surface along most of the Pecos River, and the alluvial aquifer is 
recharged by or discharges to the river (Bjorklund and Moths 1959). The alluvial aquifer is hydraulically connected to the underlying carbonate-rock aquifer by leakage through the upper confining unit of the carbonate-rock aquifer. Approximately $80 \%$ of the irrigation within the study area uses groundwater source. Most of the wells in the study area are concentrated in the central portion of the alluvial aquifer and tap water primarily from the alluvial aquifer (Hale 1961).

\subsection{Data used}

The water table elevations in the 38 monitoring wells spread across the aquifer for the irrigation years 1996 and 2003 are collected from the Office of State Engineer (OSE), Las Cruces, New Mexico, USA. Water levels in the monitoring wells are recorded during January every year. However, the number and the location of observation wells monitored every year are highly varied. The location of the observation wells and the statistical distribution of the water table elevations for the years 1996 and 2003 are represented in figure 2 . Since the variability between the two extreme measured values for each dataset is less, the probability distributions are compared with the standard normal curve. From the normal quantile-quantile plots, it is observed that the water levels from the two datasets follow near-normal distribution leading to the application of geostatistical interpolation techniques. In order to be consistent, the digitized boundary of the aquifer provided by OSE is treated as the no-flow boundary for the analysis. All monitoring wells in the study area provide the water table elevations corresponding to the alluvial aquifer. No extreme events (including floods and droughts) are reported between

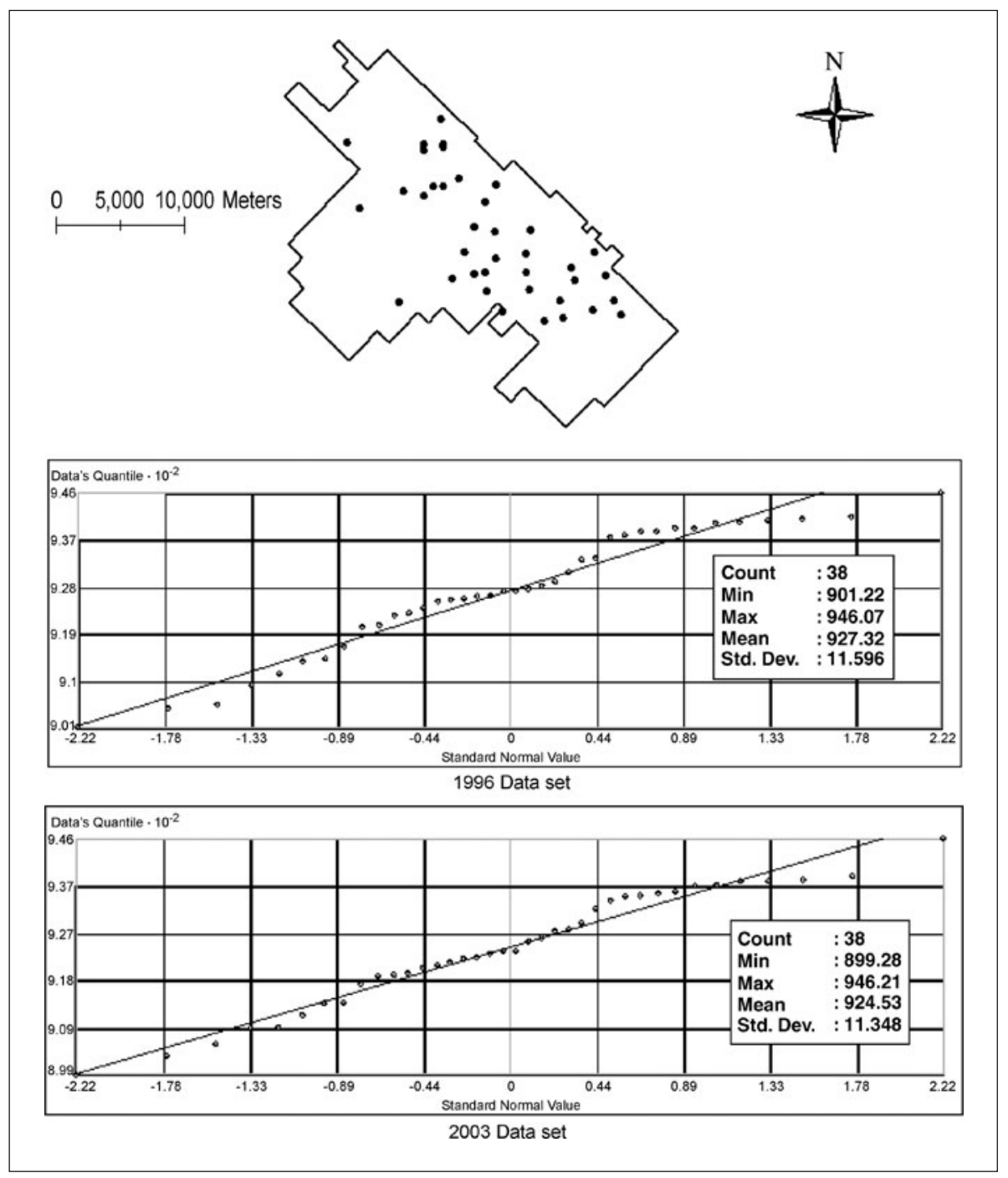

Figure 2. Statistical distribution of water table elevations during 1996 and 2003. 
1996 and 2003. Hence, temporal change in the water table profile reflects the linear changes in groundwater resulting from individual budget components.

\section{Results and discussion}

The process of generation of continuous surface of water table elevations from the measured water levels at randomly located observation wells is broadly classified into three steps.

- Preparation of omnidirectional and directional semi-variograms, thereby estimating the direction of the least trend.

- Choosing the trend order and the underlying semi-variogram model that satisfy unbiased and minimum variance conditions.

- Preparation of continuous surface of water table elevations and estimation variance using the final theoretical semi-variogram model and trend order.

The groundwater levels at unknown locations are not only a function of distance to the surrounding measured locations, but also on the direction in which the observation wells are located. However, it is difficult to examine the two perpendicular axes with maximum difference in semi-variogram values using the Geostatistical analyst ${ }^{\circledR}$. Hence
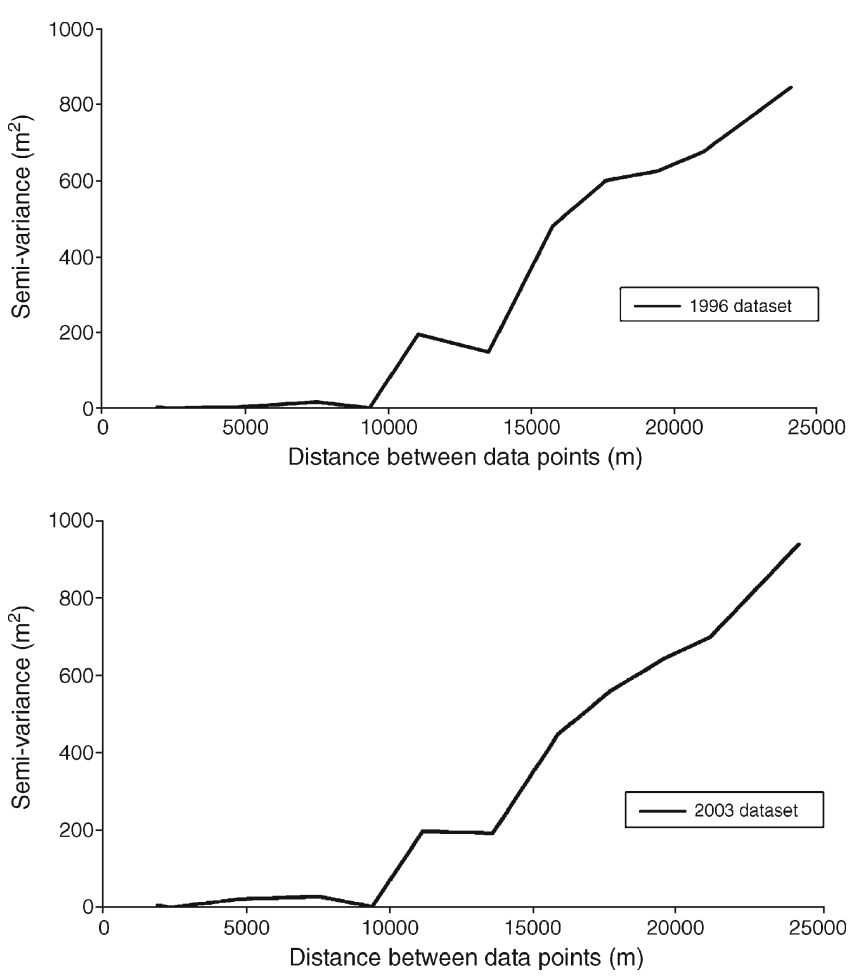

Figure 3. Omnidirectional semi-variograms for 1996 and 2003 datasets.
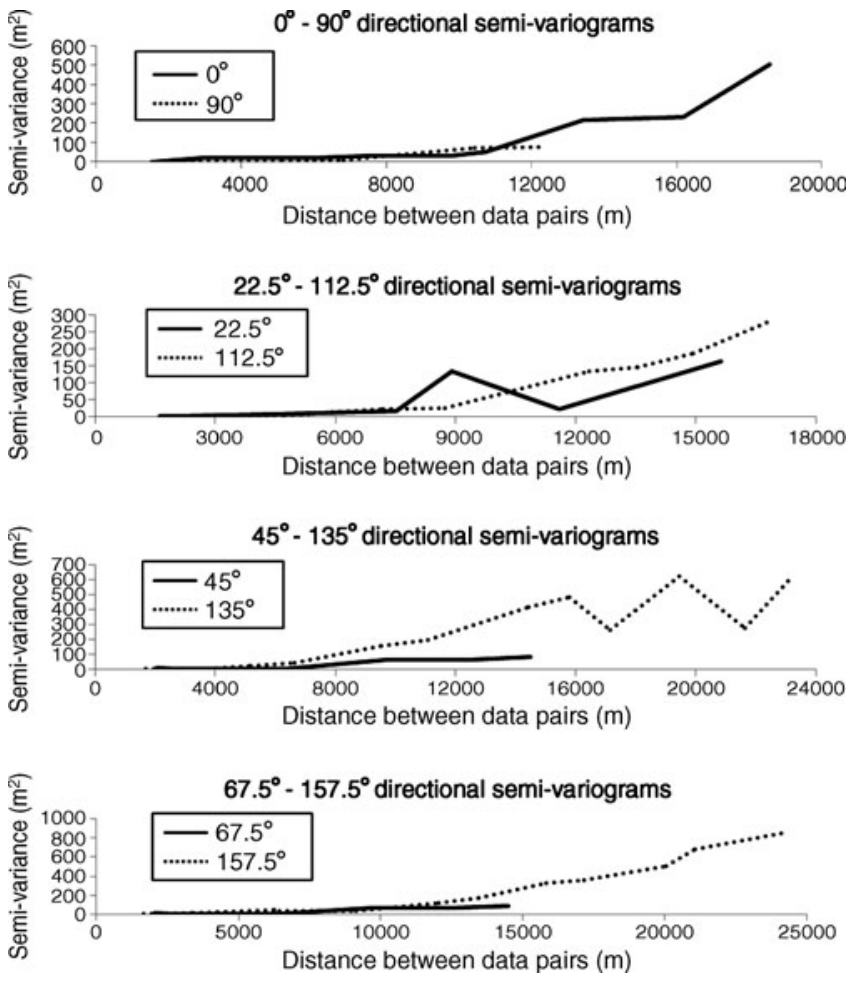

Figure 4. Directional semi-variograms (at $22.5^{\circ}$ interval) for 1996 dataset.

omnidirectional and directional semi-variograms are prepared using MATLAB ${ }^{\circledR}$ code. The program divides the distance between the data pairs into lags and calculates the semi-variance for that lag distance. Figure 3 shows omnidirectional semivariograms for 1996 and 2003 datasets. The steep slope in the semi-variogram indicates nonstationarity in groundwater levels, representing the trend. In order to assess the degree of anisotropy and major direction of spatial continuity, directional semi-variograms are generated at $22.5^{\circ}$ intervals and are shown in figure 4 for a typical 1996 dataset. From these directional semi-variograms, the two perpendicular axes that have maximum difference in semi-variogram values are observed to be $67.5^{\circ}$ and $157.5^{\circ}$ (measured clockwise from north). The high semi-variogram values in the $157.5^{\circ}$ direction indicate that the groundwater levels change at a higher spatial rate along the south-east direction, which indicates that groundwater flow is along the south-east axis. The semi-variogram in the $67.5^{\circ}$ direction that shows near absence of trend is taken as the underlying semi-variogram. The generalized MATLAB ${ }^{\circledR}$ code with necessary input files to generate the omnidirectional and directional semi-variograms (at 22.5 intervals) can be downloaded from http:// web.nmsu.edu/ phani/UniversalKriging.zip.

The semi-variogram value at the origin is almost zero for bins with low lag distances. Hence, the 
Table 1. Cross validation statistics for 1996 and 2003 datasets.

\begin{tabular}{llrll}
\hline Model & Trend order & $\begin{array}{c}\text { ME } \\
(\mathrm{m})\end{array}$ & $\begin{array}{l}\text { MSE } \\
\left(\mathrm{m}^{2}\right)\end{array}$ & KRMSE \\
\hline 1996 dataset & & & & \\
Spherical & First & -0.19 & 1.96 & 0.86 \\
& Second & -0.52 & 2.81 & 0.97 \\
Gaussian & First & -0.58 & 3.06 & 1.26 \\
& Second & -0.70 & 5.51 & 1.16 \\
Exponential & First & -0.36 & 2.01 & 0.69 \\
& Second & -0.58 & 2.65 & 0.73 \\
2003 dataset & & & & \\
Spherical & First & -0.56 & 3.60 & 0.81 \\
& Second & 0.35 & 4.79 & 1.07 \\
Gaussian & First & -0.56 & 3.62 & 0.78 \\
& Second & 0.41 & 4.79 & 1.10 \\
Exponential & First & -0.59 & 3.63 & 0.84 \\
& Second & 0.38 & 4.79 & 1.07 \\
\hline
\end{tabular}

ME: Mean error; MSE: Mean square error; KRMSE: Kriged reduced mean square error.

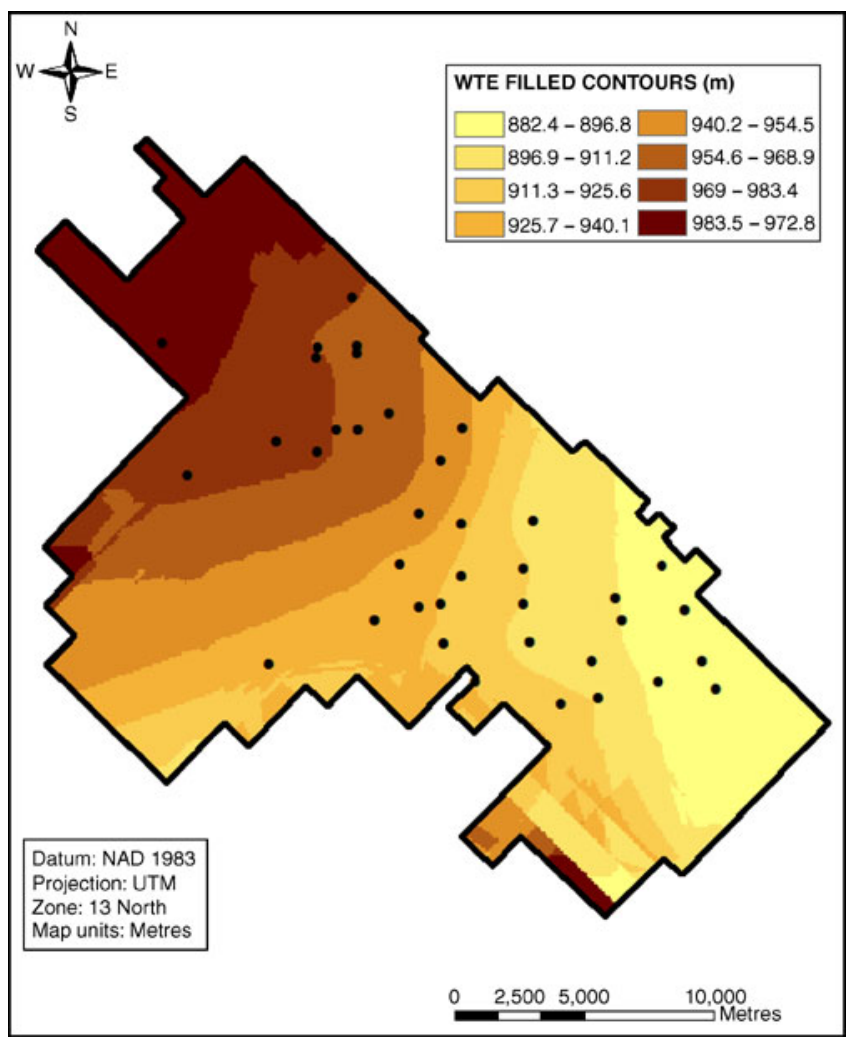

Figure 6. Kriged water table surface using 1996 dataset.

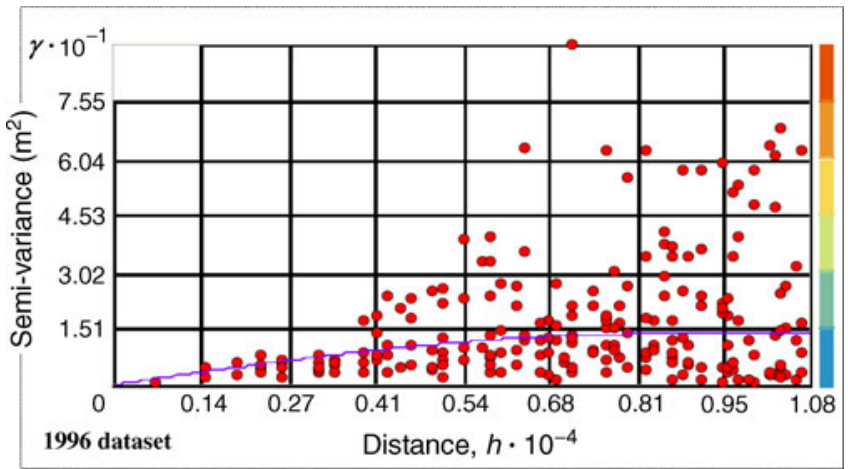

$$
\gamma(h)=13.48\left(1.5\left(\frac{h}{8305.9}\right)-0.5\left(\frac{h}{8305.9}\right)^{3}\right) \text { if } h \leq 8305.9
$$

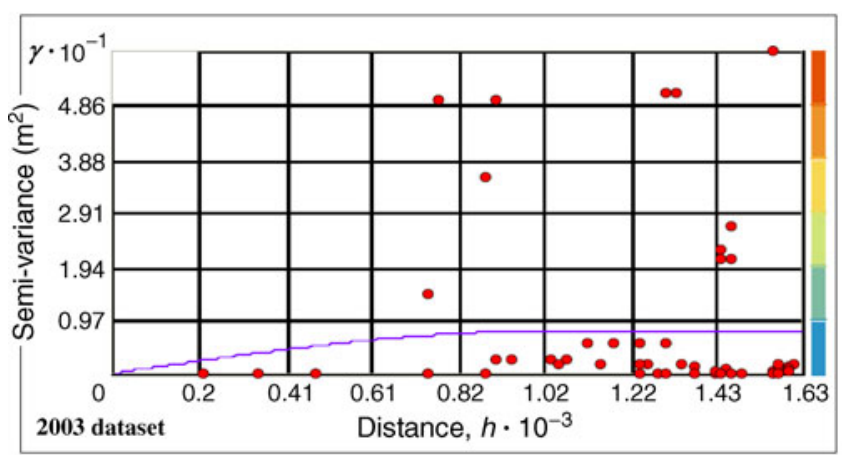

$$
\gamma(h)=7.69\left(1.5\left(\frac{h}{1036.9}\right)-0.5\left(\frac{h}{1036.9}\right)^{3}\right) \text { if } h \leq 1036.9
$$

Figure 5. Experimental and fitted semi-variogram models for 1996 and 2003 datasets.

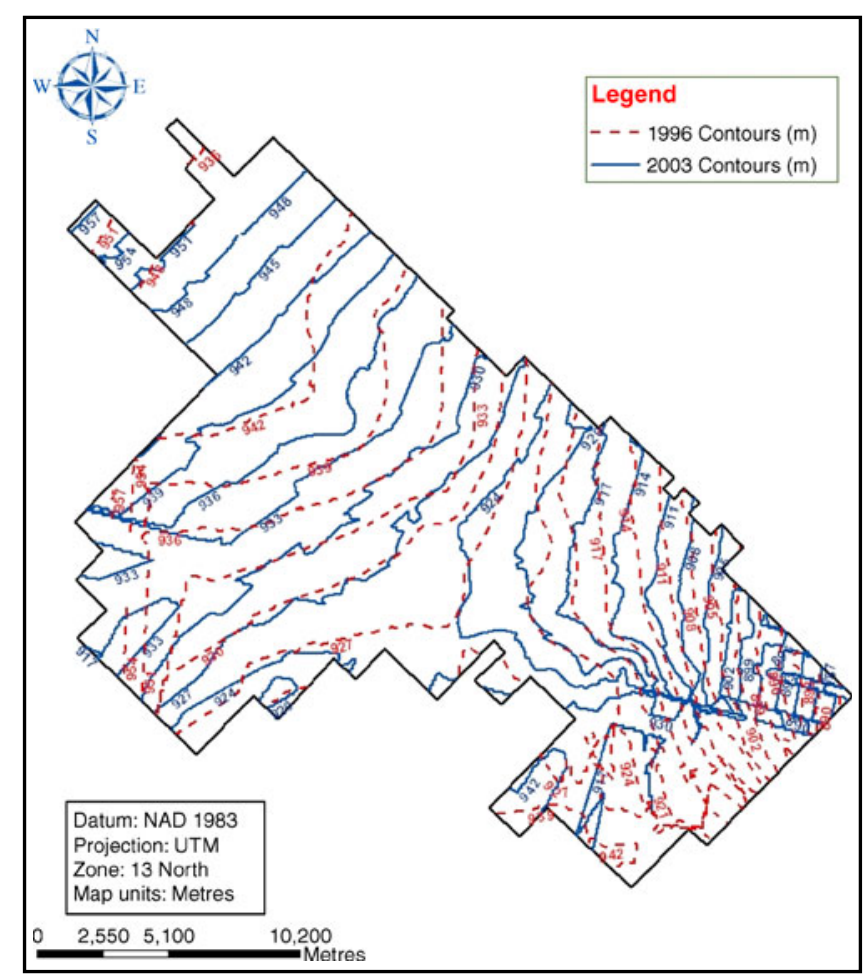

Figure 7. Comparison of contour maps of water table elevations between 1996 and 2003. 
nugget effect is ignored in the analysis. The experimental semi-variogram is compared with different theoretical models such as spherical, Gaussian, exponential models with the first and second orders of the trend. Table 1 shows the crossvalidation statistics for 1996 and 2003 datasets respectively. From these statistics, it can be concluded that the spherical model with the first order, which resulted in close to zero ME, minimum MMSE and close to 1 KRMSE, for the 1996 dataset is chosen as the final model for generating the surface of the water table elevations. Similar analysis is performed on the 2003

Table 2(a). Difference in water table elevations between 1996 and 2003 datasets.

\begin{tabular}{|c|c|c|c|}
\hline $\begin{array}{l}\text { Difference } \\
\left(y_{\mathrm{d}}\right)(\mathrm{m})\end{array}$ & $\begin{array}{l}\text { No. of data } \\
\text { pairs }(n)\end{array}$ & $\begin{array}{l}\text { Sum of differences } \\
\left(Y_{\mathrm{D}}=y_{\mathrm{d}} * n\right)(\mathrm{m})\end{array}$ & $\begin{array}{c}Y_{\mathrm{D}}^{2} \\
\left(\mathrm{~m}^{2}\right)\end{array}$ \\
\hline-5 & 5 & -25 & 625 \\
\hline-3 & 82 & -246 & 60516 \\
\hline-2 & 296 & -592 & 350464 \\
\hline-1 & 859 & -859 & 737881 \\
\hline 0 & 3328 & 0 & 0 \\
\hline 1 & 2652 & 2652 & 7033104 \\
\hline 2 & 6156 & 12312 & 151585344 \\
\hline 3 & 3621 & 10863 & 118004769 \\
\hline 4 & 5619 & 22476 & 505170576 \\
\hline 5 & 989 & 4945 & 24453025 \\
\hline 6 & 2470 & 14820 & 219632400 \\
\hline 7 & 28 & 196 & 38416 \\
\hline 8 & 118 & 944 & 891136 \\
\hline 10 & 2 & 20 & 400 \\
\hline 12 & 4 & 48 & 2304 \\
\hline 14 & 3 & 42 & 1764 \\
\hline 15 & 6 & 90 & 8100 \\
\hline 19 & 4 & 76 & 5776 \\
\hline 21 & 2 & 42 & 1764 \\
\hline Sum & 26244 & 67804 & 1027978364 \\
\hline
\end{tabular}

Table 2(b). Statistical parameters for differencing.

\begin{tabular}{lr}
\hline$n$ & \multicolumn{1}{c}{26244} \\
\hline $\mathrm{DOF}$ & 26243 \\
$\bar{Y}_{\mathrm{D}}$ & 2.5836 \\
$S_{\mathrm{D}}^{2}$ & 39164.85 \\
$S_{\mathrm{D}}$ & 197.9011 \\
$t_{\mathrm{cr}}$ & 1.645 \\
$\alpha$ & 0.05 \\
\hline
\end{tabular}

$S_{\mathrm{D}}=$ Standard deviation of the differences in water level elevations; $\mathrm{DOF}=$ Degrees of freedom; $\alpha=$ Significance level; $t_{\mathrm{cr}}=$ Critical values of $t$ statistic for a given $\alpha$ value. dataset, for which the spherical model with second order trend is fitted well. The experimental semivariogram and the best fitted theoretical models for 1996 and 2003 datasets are represented in figure 5. The semi-variogram parameters (including sill and range) that defines amplitude, and the distance beyond which autocorrelation is negligible are provided in figure 5. Since the area of interest (alluvial aquifer) is heavily stressed, groundwater flow models of the region uses a fine discretization in simulation. Hence, the water table and estimation variance surfaces are prepared at the nodes of a square grid of $100 \mathrm{~m}$ resolution to generate the corresponding contour maps.

For observing the temporal variation in groundwater levels within the study area, the contour maps of water table elevations and the estimation variance are prepared for the two datasets at 2 and $1 \mathrm{~m}$ intervals, respectively. The water table surface generated using Geostatistical analyst ${ }^{\circledR}$ for the 1996 dataset is shown in figure 6. The movement of groundwater flow in the south-east direction indicates that the groundwater in the study area behaves in response to the surface water system. The contour map of water table elevations for both the datasets is represented in figure 7. From this map, it can be concluded that there is a general decrease in water levels from 1996 to 2003 . The decrease is more significant in the northern part of the aquifer along the Pecos

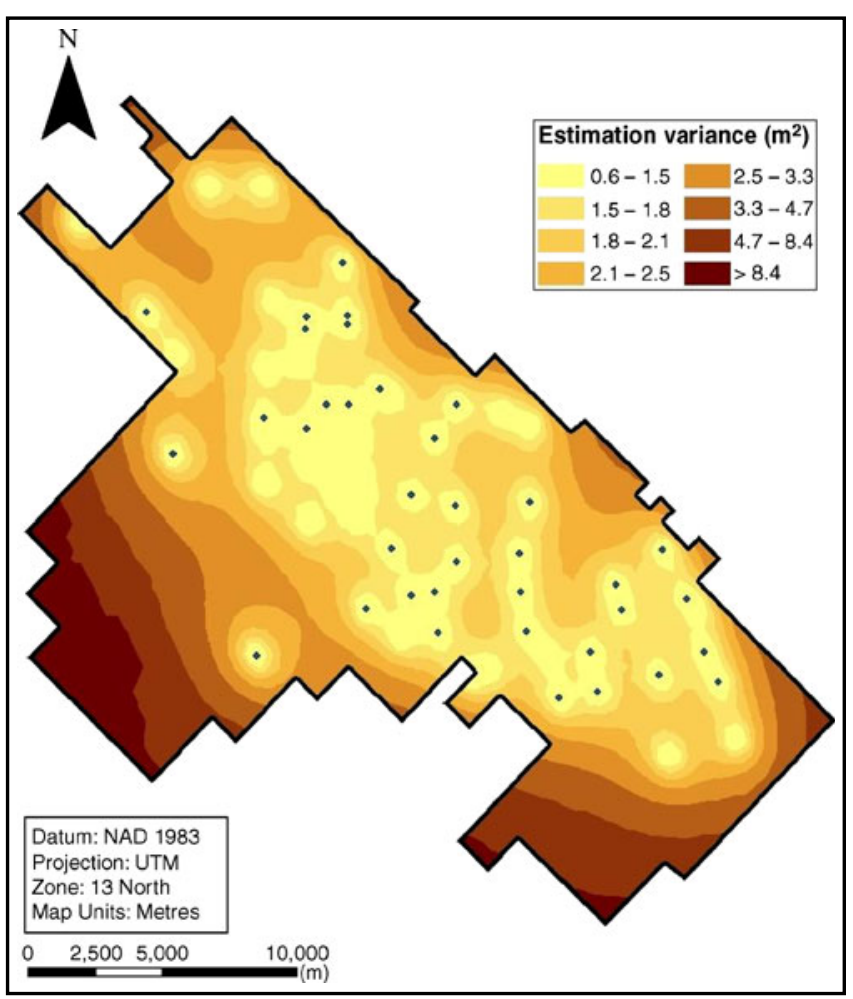

Figure 8. Kriged surface of estimation variance for 1996 dataset. 
River. In contrast, there is a slight increase in water table elevations along the central-east portion of the aquifer. A significant decrease in groundwater levels is observed in the western part of the study area. This is mainly attributed to changes in land use assisted with groundwater flows towards the river. The estimated water table elevations at each regular grid cell location during 1996 and 2003 are then compared to determine if there is a significant difference in water table profile between the 2 years. A matched pair $t$-test is performed for the difference in water table elevations at each grid cell. Null hypothesis used in statistical analysis assumes that there is no significant change in water table profile with time. Results of the matched pair $t$ test are summarized in tables $2 \mathrm{a}$ and $2 \mathrm{~b}$. Since the statistical analysis is performed on two dependent samples (the estimated water levels at regular grid cells), matched pair $t$-test is more reliable for analysing the temporal changes in the water table surface. Confidence interval test on the mean of the difference between the two datasets concludes that the decrease in water table elevations from 1996 to 2003 is between 0.6 and $4.5 \mathrm{~m}$ at $90 \%$ confidence. The error in the estimation of water table surface for 1996 dataset is shown in figure 8. From this, it can be inferred that the estimation variance is more than $8 \mathrm{~m}^{2}$ in regions where observations are not made. The estimation variance is almost absent around the monitoring wells in the central portion of the aquifer. This suggests that there is a high priority to install additional monitoring wells in the west to south-west portion of the study area for effective management of groundwater resources of the region.

\section{Conclusions}

This paper deals with the application of universal kriging to estimate the continuous surface of water table elevations and the estimation variance for the Carlsbad area alluvial aquifer in New Mexico. The data from the 38 observation wells follows near-normal distribution. A generalized MATLAB ${ }^{\circledR}$ code was developed to examine the two perpendicular axes with maximum deviation in semi-variogram values. Several combinations of neighbourhood size, polynomial trend and semi-variogram models for the residuals were tried before performing the geostatistical interpolation. Flow of groundwater in the study area is primar- ily towards the southeast along the Pecos River. Water table elevation contours for both datasets reveal that there was a significant decrease in the water table profile from 1996 to 2003. Results of the statistical analysis concluded that the decrease in water table elevations is between 0.6 and $4.5 \mathrm{~m}$ at $90 \%$ confidence. The contour map of estimation variance for both the datasets concluded that the error in the estimation of water table elevations is significant in the west and south-west portions of the aquifer due to the absence of monitoring wells.

\section{References}

ASCE Task Committee 1990a Review of geostatistics in geohydrology I: Basic concepts; J. Hydraul. Eng. ASCE 116 612-632.

ASCE Task Committee 1990b Review of geostatistics in geohydrology II: Applications; J. Hydraul. Eng. ASCE 116 633-658.

Bjorklund L J and Moths W S 1959 Geology and water resources of the Carlsbad area Eddy County, New Mexico; New Mexico Office of the State Engineer, Open file report, $59(9)$.

Dunlap L E and Spinazola J M 1984 Interpolating watertable altitudes in west-central Kansas using kriging techniques; USGS Water-Supply Paper 2238, United States Government Printing Office, Washington.

Gundogdu K S and Guney I 2007 Spatial analyses of groundwater levels using universal kriging; J. Earth Syst. Sci. 116(1) 49-55.

Hale W E 1961 Geology of groundwater in New Mexico; New Mexico Office of the State Engineer, Open file report, 61(13).

Igúzquiza E P and Olmo M C 2004 Estimation of gradients from sparse data using Universal Kriging; Water Resour. Res. 40(12) W12418.

Isaaks E H and Srivastava R M 1989 Applied Geostatistics (New York: Oxford University Press).

Johnston K, Ver Hoef J M, Krivoruchko K and Lucas N 2001 Using arc GIS-geostatistical analyst; GIS by ESRI, Redlands, USA.

Journal A G and Huijbregts C J 1978 Mining Geostatistics (London: Academic Press).

Kastelec D and Koŝmelj K 2002 Spatial interpolation of mean yearly precipitation using universal kriging; Developments in Statistics 17 149-162.

Kumar V 2007 Optimal contour mapping of groundwater levels using universal kriging - a case study; J. Hydrol. Sci. 52(5) 1039-1049.

Kumar V and Ramadevi 2006 Kriging of groundwater levels - a case study; J. Spatial Hydrol. 6(1) 81-94.

Pucci A A and Murashige J E 1987 Applications of universal kriging to an aquifer study in New Jersey; Ground Water 25(6) $672-678$.

Rouhani S 1989 Geostatistics in water resources; Proceedings of the Georgia Water Resources Conference, The University of Georgia, Georgia, 169-171. 